\title{
A Química como Vocação: Basta Melhorá-la no Ensino Médio
}

\author{
Silva, B. V.;* Rezende, M. J. C.; Hamerski, L.; Almeida, M. R.; Saldanha, L. \\ D.; Azevedo, L. T. S. A.; Abreu, G. S.; Santiago, M. A. N. T.; Bicca, R. B.; \\ Pinto, A. C.
}

Rev. Virtual Quim., 2015, 7 (3), 880-892. Data de publicação na Web: 1 de dezembro de 2014

http://www.uff.br/rvq

\section{Chemistry as a Vocation: Just Improve it in High School}

\begin{abstract}
The teaching of science at high school levels, chemistry in particular, is a portrait of the educational deficit that has been accumulated by Brazil throughout its history. Besides the lack of infrastructure for experimental classes, teachers of this discipline are severely lacked. This article summarizes the results of projects submitted to two calls: Call FAPERJ № 08/2012 - Support Production of Teaching Materials for Teaching Activities and/or Survey - 2012, of witch objective was to produce 300 kits containing laboratory materials to be distributed to teachers of Chemistry of High Schools of RJ State and Municipal Networks; and FAPERJ № 31/2012 - Support Improve Education in Public Network Schools in the State of Rio de Janeiro - 2012, whose objective was to organize a laboratory of Chemistry for experimental classes in Colégio Estadual José Veríssimo, located in Magé city. Both the production of kits and the organization of the chemical laboratory were successfully completed and are impacting positively on various Rio de Janeiro schools, in particular, on the Colégio Estadual José Veríssimo, which became a model for Magé and all Rio de Janeiro state schools.
\end{abstract}

Keywords: Chemistry teaching; High school; Kits production; teaching material.

\section{Resumo}

O ensino de ciências no Ensino Médio, em particular a Química, é um retrato do atraso da educação no Brasil ao longo de sua história. Além da falta de infraestrutura para as aulas experimentais, há uma carência muito grande de professores dessa disciplina. Este artigo resume os resultados obtidos em projetos submetidos a dois editais: Edital FAPERJ № 08/2012 - Apoio à Produção de Material Didático para Atividades de Ensino e/ou Pesquisa - 2012, cujo objetivo foi confeccionar 300 kits com materiais de laboratório para serem distribuídos a professores de Química do Ensino Médio das redes Estadual e Municipal do RJ; e o Edital FAPERJ № 31/2012 - Apoio à Melhoria do Ensino em Escolas da Rede Pública Sediadas no Estado do Rio de Janeiro - 2012, cujo objetivo foi criar um laboratório de Química para aulas experimentais no Colégio Estadual José Veríssimo, no Município de Magé. Tanto a confecção dos kits como a criação do laboratório químico Professor Joab Trajano, foram realizadas com sucesso e estão repercutindo de maneira positiva em diversas escolas do Rio de Janeiro, em especial, no Colégio Estadual José Veríssimo, que se tornou um exemplo de modelo para Magé e para todo o estado do Rio de Janeiro.

Palavras-chave: Ensino de química; Ensino Médio; Confecção de kits; Material didático.

* Universidade Federal do Rio de Janeiro, Instituto de Química-CT, Bloco A, Cidade Universitária, CEP 21945-970, Rio de Janeiro-RJ, Brasil.

$M$ barbara.iq@gmail.com

DOI: $10.5935 / 1984-6835.20150045$

Rev. Virtual Quim. |Vol 7| | No. 3| |880-892| 


\title{
A Química como Vocação: Basta Melhorá-la no Ensino Médio
}

\author{
Bárbara V. Silva, ${ }^{\mathrm{a}, *}$ Michelle Jakeline C. Rezende, ${ }^{a}$ Lidilhone Harmerski, ${ }^{\mathrm{b}}$ \\ Márcia Rosa Almeida, ${ }^{a}$ Leandro D. Saldanha, ${ }^{a, c}$ Lucas T. S. A. Azevedo, ${ }^{a}$ \\ Gabriel S. Abreu, ${ }^{a, c}$ Maria Angélica N. T. Santiago, ${ }^{c}$ Ricardo B. de \\ Alencastro, ${ }^{\mathrm{a}}$ Angelo C. Pinto ${ }^{\mathrm{a}}$ \\ a Universidade Federal do Rio de Janeiro, Instituto de Química-CT, Bloco A, Cidade \\ Universitária, CEP 21945-970, Rio de Janeiro-RJ, Brasil. \\ ${ }^{\mathrm{b}}$ Universidade Federal do Rio de Janeiro, Instituto de Pesquisa de Produtos Naturais, Centro \\ de Ciências da Saúde, Cidade Universitária, CEP 21941-902, Rio de Janeiro-RJ, Brasil. \\ c Colégio Estadual José Veríssimo, Av. Duque de Caxias 627, Vila Inhomirim, CEP 25935-000, \\ Magé-RJ, Brasil. \\ * barbara.iq@gmail.com
}

Recebido em 6 de novembro de 2014. Aceito para publicação em 30 de novembro de 2014

\section{Introdução}

1.1. O Ensino no Brasil

1.2. O Ensino de Ciências no Brasil

\section{Projetos na área da Educação Básica, em Química, no Rio de Janeiro}

2.1. Confecção de kits para a realização de aulas experimentais de química para estudantes do Ensino Médio

2.2. Criação do laboratório químico no Colégio Estadual José Veríssimo

2.3. Realização de seminários

\section{Conclusão}

\section{Introdução}

\subsection{O Ensino no Brasil}

O Brasil é um País de território continental e com grandes contrastes. Além disso, suas diferenças variam de região para região. Essas vão das características geográficas, culturas diferentes e diversidade étnica às desigualdades sociais. As grandes diferenças sociais decorrentes da distribuição desigual de renda se manifestam na baixa escolaridade de uma parcela enorme da juventude brasileira.

Segundo o Secretário de Educação de Santa Catarina, Eduardo Deschamps, 15,8 \% dos brasileiros com mais de 15 anos eram analfabetos em 1995, e hoje este número diminuiu para $8,8 \%$. Apesar disso, um número inferior a $30 \%$ dos estudantes que finalizam o Ensino Médio conseguem chegar 
à universidade, e 1,6 milhão de jovens com idades entre 15 e 17 anos não estão na escola. ${ }^{1}$

A mudança do quadro atual da educação no Brasil exige investimento contínuo em recursos humanos e materiais em todas as etapas da educação básica, com foco na sala de aula. Dos recursos públicos para a Educação, $65 \%$ são para o Ensino Fundamental, $13 \%$ para o médio, $7 \%$ para o infantil e $15 \%$ para o superior. ${ }^{2}$ Que a criança deve ser a prioridade do governo "Children first", ${ }^{3}$ não há dúvida, e deve-se reconhecer que houve substancial investimento no Ensino Fundamental. Mas deve ser meta do governo atingir também o Ensino Médio, onde há falta de estrutura e professores sem formação compatível com as disciplinas que lecionam. É muito comum, por exemplo, ver profissionais formados em química ou matemática dando aulas de física, e professores de educação física dando aulas de biologia, e por aí vai.

O problema é de grande dimensão e sua solução depende do envolvimento dos governos Federal, Estadual e Municipal, de universidades e de todos aqueles que se dedicam à educação. Milagres não acontecem, mas lições como a da agora famosa cidade do Piauí, Cocal dos Alves, cujos estudantes vêm alcançando resultados excelentes nas olimpíadas de Matemática ${ }^{4}$, e da Escola Municipal José de Carvalho Souza situada em Coruripe, um município a 85 quilômetros de Maceió com Índice de Desenvolvimento da Educação Básica (IDEB) de 5,8, bem superior à media nacional de 4,3 (Ensino Fundamental e Médio), ${ }^{5}$ devem ser seguidas. Há vários bons exemplos a seguir de melhorias na educação pelo mundo afora. ${ }^{6}$

Algumas ações de governo vêm tentando estimular os jovens para os cursos de Licenciatura, apesar de a quase totalidade das instituições públicas de ensino superior ainda considerarem as Licenciaturas de importância menor dentre seus cursos. ${ }^{7,8} \mathrm{O}$ CNPq, por exemplo, criou o Programa Institucional de Bolsas de Iniciação Científica para o Ensino Médio - PIBIC- EM. Já a CAPES lançou editais para vários Programas: Programa Institucional de Bolsa de Iniciação à Docência (PIBID); Programa de Consolidação das Licenciaturas (PRODOCÊNCIA); Programa Novos Talentos; Plano Nacional de Formação de Professores da Educação Básica - PARFOR; Programa de Apoio a Laboratórios Interdisciplinares de Formação de Educadores - Life; Observatório da Educação (OBEDUC) em parceria com o INEP e a SECADI. ${ }^{9}$

A FAPERJ lança anualmente, desde 2007, o edital Apoio à Melhoria do Ensino em Escolas da Rede Pública Sediadas no Estado do Rio de Janeiro e fornece bolsas no Programa Jovens Talentos para alunos do Ensino Médio e bolsas de treinamento e capacitação técnica (TCT) para professores das escolas públicas do Rio de Janeiro. ${ }^{10}$

\subsubsection{Ensino de Ciências no Brasil}

Não é novidade que o ensino de ciências, em particular o de Química, não vai bem e que faltam professores dessa disciplina no Ensino Médio. Entre os muitos fatores que contribuem para agravar, a cada ano, esse quadro, cujo resultado mais visível é o baixo desempenho dos estudantes brasileiros no maior exame mundial de ciências para estudantes de 15 anos, aplicado pelo Programa Internacional de Alunos (PISA Programme for International Student Assessment), ${ }^{11}$ pode-se destacar a falta de laboratórios de ciências e de material didático para as aulas experimentais de Química.

O livro didático impresso, apesar de toda a sua importância para o ensino de Química, não é suficiente para motivar a maior parte dos estudantes a aprender esta disciplina. Experiências recentes em decorrência das comemorações, em 2011, do Ano Internacional da Química (AIQ), mostraram que é possível mobilizar e interessar milhares de crianças e adolescentes para a realização de experimentos simples. Uma das atividades mais importantes e marcantes do AIQ foi o 
experimento global "pH do Planeta". Devido a enorme repercussão alcançada, esta atividade foi incluída pelo Ministério de Ciência, Tecnologia e Inovação (MCT\&l) nas comemorações da Semana Nacional de Ciência e Tecnologia. ${ }^{12}$

Ao ligarem Ciência, Tecnologia e Educação os pesquisadores do Instituto Nacional de Ciência e Tecnologia de Energia e Ambiente (INCT - E\&A), mostraram que é possível se alcançar quando se mobiliza estudantes, pesquisadores e educadores para fazerem da ciência um instrumento voltado para a educação. ${ }^{13}$

Não faltam bons exemplos no País do envolvimento de cientistas com a formação de professores de ciências e com estudantes do Ensino Médio e Fundamental. Para citar apenas um de grande sucesso, é o coordenado, desde a metade da década de oitenta, pelo Professor Leopoldo de Meis, do Instituto de Bioquímica Médica da Universidade Federal do Rio de Janeiro (IBqM-UFRJ). Seu sucesso foi tanto, que este projeto se expandiu para 13 universidades públicas e hoje envolve dezenas de grupos de pesquisa. ${ }^{14}$ Este projeto já beneficiou milhares de estudantes. Muitos dos que fizeram os cursos de férias no IBqM são hoje professores universitários com a titulação de doutor.

\section{Projetos na área da Educação Básica, em Química, no Rio de Janeiro}

Em 2012, uma equipe composta por 1 pesquisador sênior e 4 pesquisadoras emergentes submeteu duas propostas para dois editais da FAPERJ voltados à melhoria da educação no Rio de Janeiro:

Edital FAPERJ № 08/2012 - Programa Apoio à Produção de Material Didático para Atividades de Ensino e/ou Pesquisa - 2012. O objetivo da proposta foi confeccionar 300 kits contendo material de laboratório para serem distribuídos a professores de Química do Ensino Médio das redes Estadual e Municipal do RJ;

$>$ Edital FAPERJ № 31/2012 - Programa Apoio à Melhoria do Ensino em Escolas da Rede Pública Sediadas no Estado do Rio de Janeiro - 2012. O objetivo da proposta foi criar um laboratório de Química para aulas experimentais no Colégio Estadual José Veríssimo, na Av. Duque de Caxias 627, Vila Inhomirim, Município de Magé, Estado do Rio de Janeiro, para estudantes do Ensino Médio.

Com recursos desses dois editais os objetivos de cada proposta foram plenamente alcançados e podem servir de modelo para projetos semelhantes.

O propósito deste artigo é descrever os resultados alcançados com os recursos dos editais FAPERJ № 08/2012 e FAPERJ № $31 / 2012$, e estimular pesquisadores da área de Química, especialmente os Cientistas do Nosso Estado da FAPERJ, a enveredarem pela aventura da educação no Ensino Médio.

2.1. Confecção de kits para a realização de aulas experimentais de química para estudantes do Ensino Médio

Os 300 kits foram confeccionados em caixas de madeira com divisórias e contêm pipetas Pasteur, peras para pipetas, proveta, balão, béquer, óculos de segurança, espátula, tubo capilar, tubos de ensaio e vidro de relógio (Figura 1). 
Silva, B. V. et al.
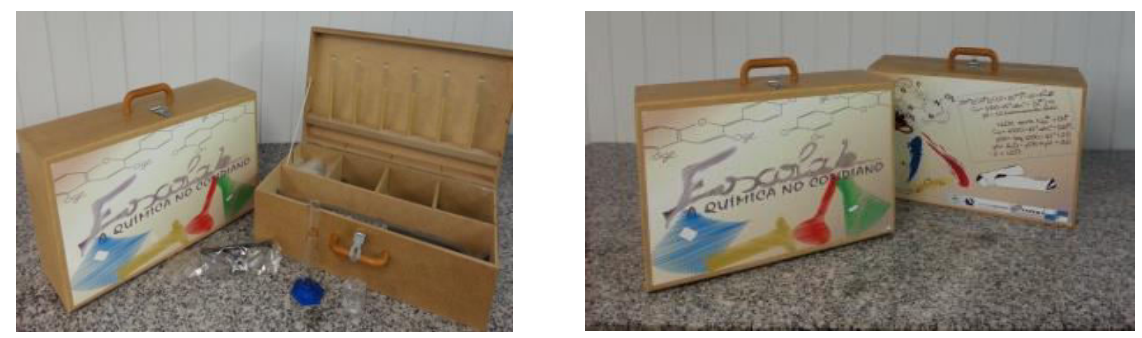

Figura 1. Kits confeccionados pela equipe do projeto

A arte dos adesivos, colados na parte frontal e de trás da maleta, foi criada por dois estudantes, um de graduação, Douglas Klem Portugal do Amaral, na época estudante do Instituto Federal de Educação de Nilópolis, e outro do Programa de Pós-graduação em Química da UFRJ, Rômulo Gabriel de Miranda de Paula Pinto.

O empenho de dois alunos do Ensino Médio, um bolsista PIBIC-EM do CNPq, Lucas Terêncio Soares Alves Azevedo (aluno do Colégio Estadual Sargento Wolff), e o outro bolsista do Programa Jovens Talentos da FAPERJ, Gabriel Siqueira de Abreu (aluno do Colégio Estadual José Veríssimo), foi fundamental para a montagem dos kits. Os estudantes protegeram as vidrarias com plástico-bolha e acomodaram espumas de 1 $\mathrm{cm}$ de espessura em todas as caixas de madeira, possibilitando um transporte seguro do material.

Os dois bolsistas participaram ativamente do projeto. Assistiram as reuniões científicas semanais do grupo de pesquisa, ministraram seminários sobre os seus trabalhos e fizeram demonstrações para estudantes do Ensino Médio na Feira de Ciências da FAPERJ.

Os kits vêm sendo distribuídos para diversas escolas públicas (Tabela 1), possibilitando a execução de experimentos simples.

Além da distribuição dos kits, fez parte das metas do projeto a confecção de cartilhas eletrônicas e impressas voltadas para professores e estudantes do Ensino Médio, contendo sugestões de experimentos. As cartilhas podem ser acessadas no site http://www.i-flora.iq.ufri.br/.

Tabela 1. Instituições que receberam os kits*1

\begin{tabular}{|c|c|}
\hline Instituição & $\begin{array}{c}\text { Número de kits } \\
\text { doados }^{* 2}\end{array}$ \\
\hline $\begin{array}{c}\text { Colégio Estadual José Veríssimo } \\
\text { Av. Duque de Caxias, Vila Inhomirim, Magé - RJ }\end{array}$ & 10 \\
\hline $\begin{array}{c}\text { Instituto Federal de Roraima *3 } \\
\text { Rua Fernão Dias Paes Leme, 11, Calungá, Boa Vista-RR }\end{array}$ & 30 \\
\hline $\begin{array}{c}\text { Colégio Estadual Poeta Mário Quintana } \\
\text { Rua Coronel França Leite, 2018, Centro-Nilópolis - RJ }\end{array}$ & 10 \\
\hline $\begin{array}{c}\text { Colégio Estadual Joaquim Leitão } \\
\text { Rua Waldemar Lima Teixeira, SN, Santo Aleixo - RJ }\end{array}$ & 10 \\
\hline $\begin{array}{c}\text { Colégio Estadual Visconde de Sepetiba } \\
\text { Praça da bandeira, 308 Centro, Magé - RJ }\end{array}$ & 10 \\
\hline $\begin{array}{c}\text { Colégio Estadual Cortume Carioca } \\
\text { Rua Albertino Xavier, S/N Iconha, Guapimirim - RJ }\end{array}$ & 10 \\
\hline Centro de Ensino Integrado Agroecológico Barão de Langsdorff & 10 \\
\hline
\end{tabular}




\begin{tabular}{|c|c|}
\hline Estrada da Conceição, 4601, Fazenda Conceição de Suruí, Magé - RJ & \\
\hline $\begin{array}{l}\text { Colégio Estadual Profo Maria José Raunheitti Duccini } \\
\text { Rua Prof Maria Emília Cardoso Lima, 304, Nova Iguaçu - RJ }\end{array}$ & 1 \\
\hline $\begin{array}{l}\text { Colégio Estadual Sargento Wolff } \\
\text { Estrada Manuel Sá, } s / n \text { Duque de Caxias - RJ }\end{array}$ & 1 \\
\hline $\begin{array}{l}\text { Colégio Estadual Honduras } \\
\text { Praça Seca, 12, Rio de Janeiro - RJ }\end{array}$ & 1 \\
\hline $\begin{array}{l}\text { Escola Municipal Rosa da Fonseca } \\
\text { Av. Duque de Caxias, 30, Deodoro - RJ }\end{array}$ & 1 \\
\hline $\begin{array}{l}\text { Escola Técnica Estadual João Luiz do Nascimento } \\
\text { Rua Luís de Lima, 272, Centro, Nova Iguaçu - RJ }\end{array}$ & 1 \\
\hline $\begin{array}{l}\text { Escola Municipal Tenente General Napion } \\
\text { Avenida Almirante Frontin, 50, Ramos - RJ }\end{array}$ & 1 \\
\hline $\begin{array}{l}\text { Colégio Estadual Almirante Frederico Villar } \\
\text { Praça Castelo Branco, 13, Praia dos Anjos - RJ }\end{array}$ & 1 \\
\hline $\begin{array}{l}\text { Colégio Estadual Sargento Antônio Ernesto } \\
\text { Rua Otávio Teixeira - Cabuçu, Nova Iguaçu - RJ }\end{array}$ & 1 \\
\hline $\begin{array}{l}\text { Ciep } 131 \text { - Prof }{ }^{\circ} \text { Armanda Alvaro Alberto } \\
\text { Rua Solange, } 7 \text {, Jardim Leal - } R \text { JJ }\end{array}$ & 1 \\
\hline $\begin{array}{l}\text { Colégio Estadual Compositor Luiz Gonzaga } \\
\text { Rua Escritor Ubaldo Soares Filho, 128, Centro, Rio de Janeiro - RJ }\end{array}$ & 1 \\
\hline $\begin{array}{l}\text { Escola Municipal } 25 \text { de abril } \\
\text { Rua Mamoré, 78, Freguesia Jpa, RJ }\end{array}$ & 1 \\
\hline $\begin{array}{l}\text { Colégio Estadual Paraíba } \\
\text { Estrada Marechal Alencastro, 4035, Anchieta, Rio de Janeiro - RJ }\end{array}$ & 4 \\
\hline $\begin{array}{l}\text { Colégio Estadual Machado de Assis } \\
\text { Rua Desembargador Lima Castro, 97,Fonseca, Niterói - RJ }\end{array}$ & 3 \\
\hline $\begin{array}{l}\text { Colégio Universitário Geraldo Reis } \\
\text { Rua Alexandre Moura, 8, São Domingos, Niterói - RJ }\end{array}$ & 20 \\
\hline $\begin{array}{l}\text { CIEP Brizolão 451-Eliza Antônia Rainho Dias } \\
\text { Rua Augusta de Jesus, SNo - João Caetano, Itaboraí - RJ }\end{array}$ & 5 \\
\hline $\begin{array}{l}\text { Colégio Estadual Antônio Houaiss } \\
\text { Rua Maranhão, 530, Meier, RJ }\end{array}$ & 4 \\
\hline $\begin{array}{l}\text { Colégio Estadual de Magé } \\
\text { Rua Comendador Reis. } S / N \text {, Centro, Magé - RJ }\end{array}$ & 10 \\
\hline $\begin{array}{l}\text { Instituto Federal do Rio de Janeiro } \\
\text { Rua Senador Furtado, 121, Maracanã, Rio de Janeiro - RJ }\end{array}$ & 5 \\
\hline Total & 152 \\
\hline
\end{tabular}

${ }^{* 1}$ As doações continuarão até a finalização dos $300 \mathrm{kits;} *{ }^{2}$ Os kits foram doados mediante a entrega de ofício assinado pela Direção da escola, com a solicitação do material. O número de kits doados correspondeu à demanda apresentada pelo professor de Química da escola.

Os professores que receberam os kits têm enviado mensagens para a equipe do projeto dizendo que as aulas experimentais vêm aumentando o interesse dos alunos pela Química.
2.2. Criação do laboratório químico no Colégio Estadual José Veríssimo

O Colégio Estadual José Veríssimo localiza- 
se no Município de Magé, que tem 244.334 habitantes, IDEB de $4,9^{5}$, Índice de Desenvolvimento Humano (IDH) de 0,746 e uma área de $386,61 \mathrm{Km}^{2}$. O Município limita- se ao norte com Petrópolis, oeste com Duque de Caxias, leste com o município de Guapimirim e ao sul com a Baía de Guanabara (Figura 2).

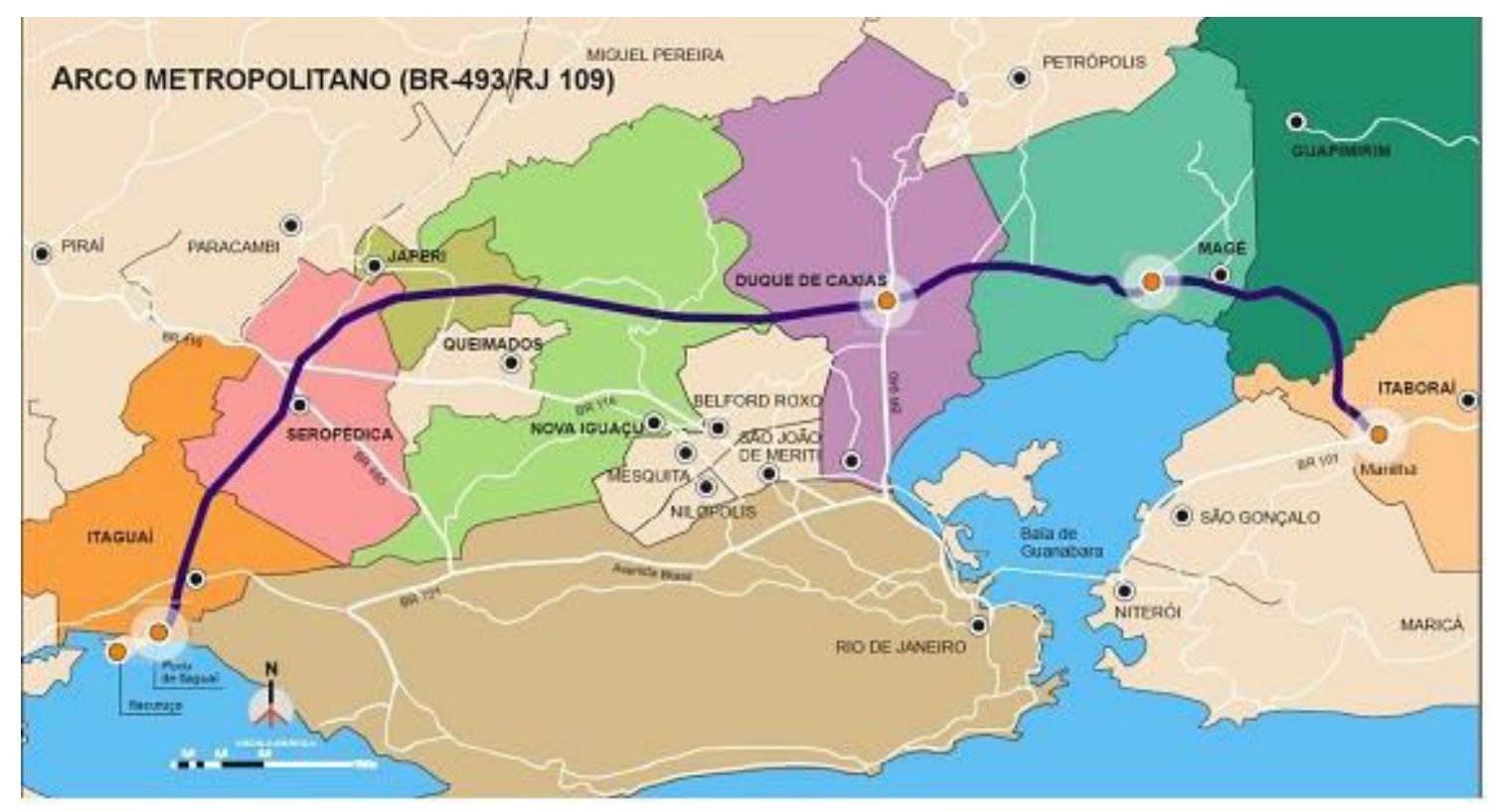

Figura 2. Mapa do arco metropolitano. Fonte: $\underline{\text { http://www.obras.ri.gov.br }}$

O Colégio Estadual José Veríssimo tem atualmente 1330 alunos que se dividem em três turnos de 7:00 $\mathrm{h}$ às 22:40 $\mathrm{h}$ (Quadro 1 ). Dessa forma, a equipe do projeto idealizou que o investimento em ações nesta escola significaria criar oportunidades de crescimento para um grande número de jovens do Município.

O Colégio Estadual José Veríssimo possuía em suas dependências uma sala de $50 \mathrm{~m}^{2}$ que vinha sendo subutilizada como depósito de material escolar fora de uso. Nesta sala foi montado um laboratório para aulas experimentais e demonstrativas de química. Antes da construção das bancadas, refez-se totalmente a parte elétrica e hidráulica e a adaptação de janelas e portas (Figura 3).

Os equipamentos, vidrarias e materiais básicos para realização de experimentos adquiridos para o laboratório são descritos na Tabela 2. 


\section{COLÉGIO ESTADUAL JOSÉ VERÍSSIMO (IDEB $=3,9)^{4}$}

Endereço: AV. DUQUE DE CAXIAS 627-VILA INHOMIRIM-MAGÉ-RJ-CEP 25935-000; TEL: (021) 2739-8684; e-mail: colegioverissimo@ibest.com.br

CNPJ- 01.655.418/0001-08

Funcionamento: 3 turnos de 7:00 h às 22:40 h

Cursos: Ensino fundamental II- 9 turmas; Curso normal- 11 turmas; Ensino médio diurno8 turmas; Ensino médio noturno- 10 turmas; Programa autonomia- 01 turma; Programa mais educação- 4 turmas com total de 100 alunos.

Diretora geral- MARIA ANGÉLICA DAS NEVES TEIXEIRA SANTIAGO

Diretoras adjuntas- Regina Célia de Medeiros Botelho; Márcia Cristina Magalhães De

Abreu

Coordenadora pedagógica- Dagmar Maria da Silva

Número total de alunos- 1330

Professores regentes- 93

Professores extra-classe- 17

Professores de química- 03

Quadro 1. Panorama das atividades desenvolvidas e da equipe integrante do Colégio Estadual José Veríssimo

Tabela 2. Descrição de equipamentos, vidrarias e materiais básicos adquiridos para o laboratório de química

\begin{tabular}{|c|c|c|}
\hline Equipamentos & $\begin{array}{c}\text { Placa de aquecimento e agitação; capela com exaustor; balança semi-analítica; } \\
\text { geladeira; centrífuga; bomba de vácuo; destilador; estufa; chuveiro de emergência } \\
\text { com lava olhos; manta para balão de } 500 \mathrm{~mL} \text {; manta para balão de } 1000 \mathrm{~mL}\end{array}$ \\
\hline $\begin{array}{c}\text { Tubos para centrífuga; Kitassatos, funis de Büchner; funis de separação; suportes } \\
\text { de aço para funis; barrilete para água destilada; buretas; pinças; tubos de Thiele; } \\
\text { tubos capilar; condensadores; cadinhos de porcelana; provetas; copos Bécher; } \\
\text { Materiais Básicos } \\
\text { frascos Erlenmeyer; placas de Petri; vidros de relógio; balões de fundo redondo; } \\
\text { espátulas; material completo para destilação; dessecador; pipetas; extratores } \\
\text { Soxhlet; barras magnéticas; tubos de ensaio; suportes para tubo de ensaio; mufas; } \\
\text { suportes universal; alongas de borracha; lâmpada UV; tetinas; placas } \\
\text { cromatográficas; papel de filtro; papel de tornassol; escova para vidrarias }\end{array}$ \\
\hline
\end{tabular}


Silva, B. V. et al.
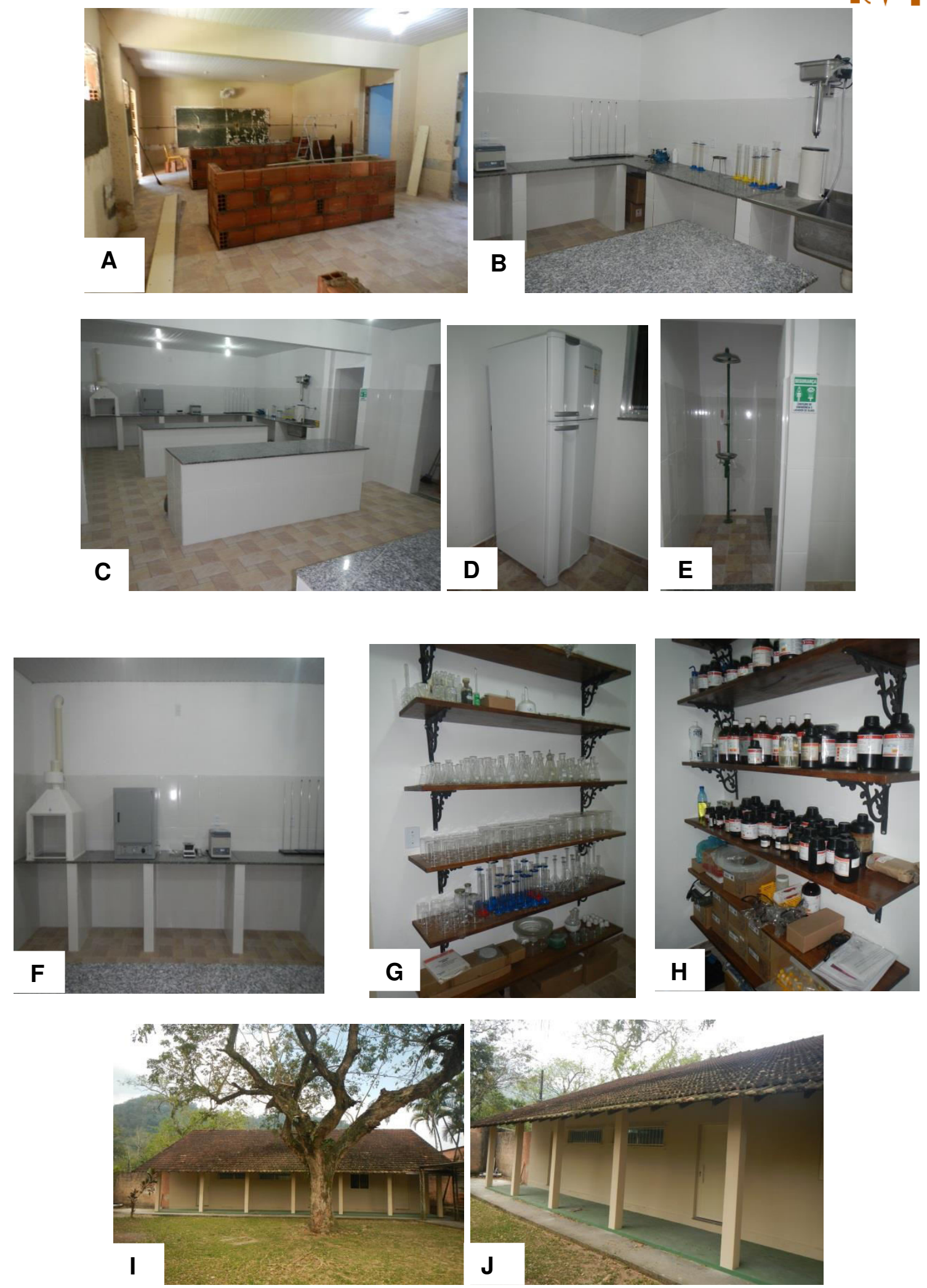

Figura 3. A) Início dos serviços de adequação; B-H) Vista do laboratório após os serviços de adequação; I-J) Vista externa do laboratório

O professor de Química do Colégio, Leandro Damiano Saldanha, foi bolsista de treinamento e capacitação técnica (TCT) da
FAPERJ no período da vigência do projeto. Além de participar da montagem dos kits e do desenvolvimento de experimentos 
simples, descritos nas cartilhas mencionadas no item 2, conjuntamente com os estudantes bolsistas do Ensino Médio, teve a tarefa de coordenar as adaptações realizadas para a criação do laboratório químico. É importante ressaltar que o sucesso do projeto também se deveu ao engajamento deste professor e do apoio total da Diretora Maria Angélica das Neves Teixeira Santiago.

A inauguração do laboratório foi realizada no dia 06 de setembro de 2013, e a cerimônia de inauguração contou com a presença do Diretor Científico da FAPERJ Jerson Lima da Silva, do assessor da Diretoria Científica da
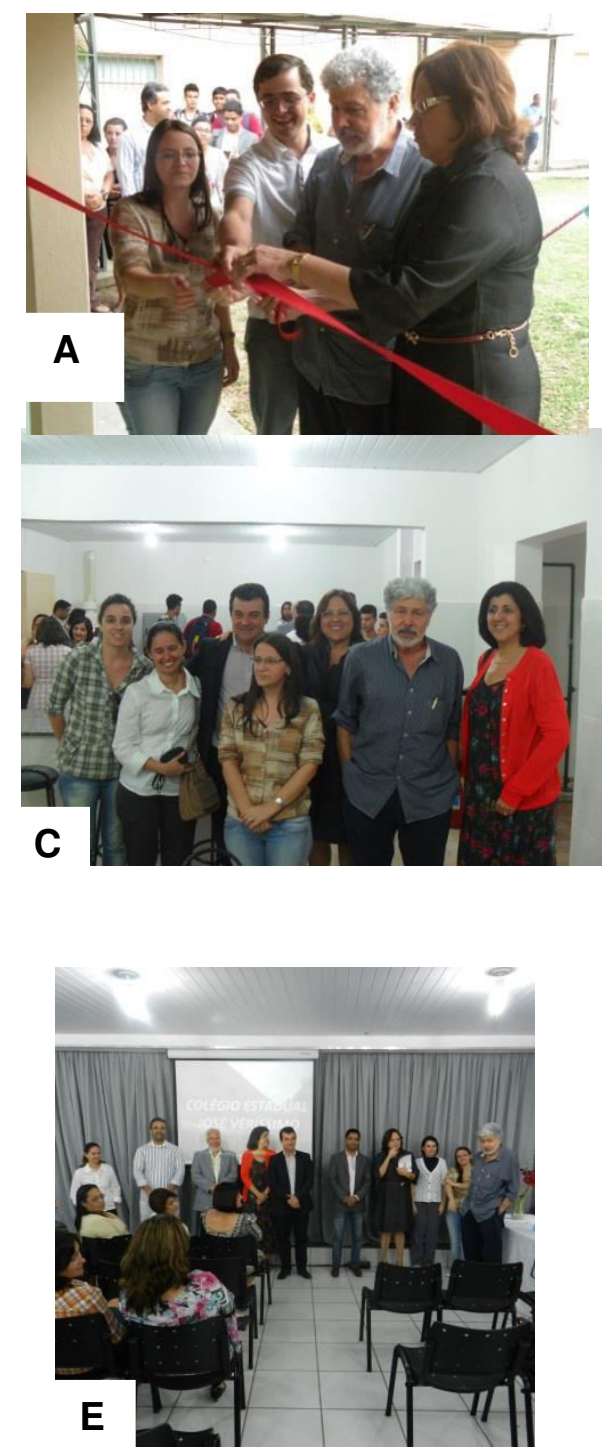

FAPERJ e presidente da Sociedade Brasileira de Química (SBQ) Vitor Francisco Ferreira, do representante da CAPES, o coordenadorGeral de Programas de Valorização do Magistério, Helder Eterno da Silveira, do Secretário Regional da SBQ Fernando de Carvalho da Silva, da Diretora do Instituto de Química da UFRJ Cássia Curan Turci, do coordenador do projeto Angelo da Cunha Pinto e de sua equipe, além de integrantes da diretoria da escola e membros da Secretaria Estadual de Educação (Figura 4). Uma nota publicada no site da FAPERJ divulgou a cerimônia de inauguração (Quadro 2).
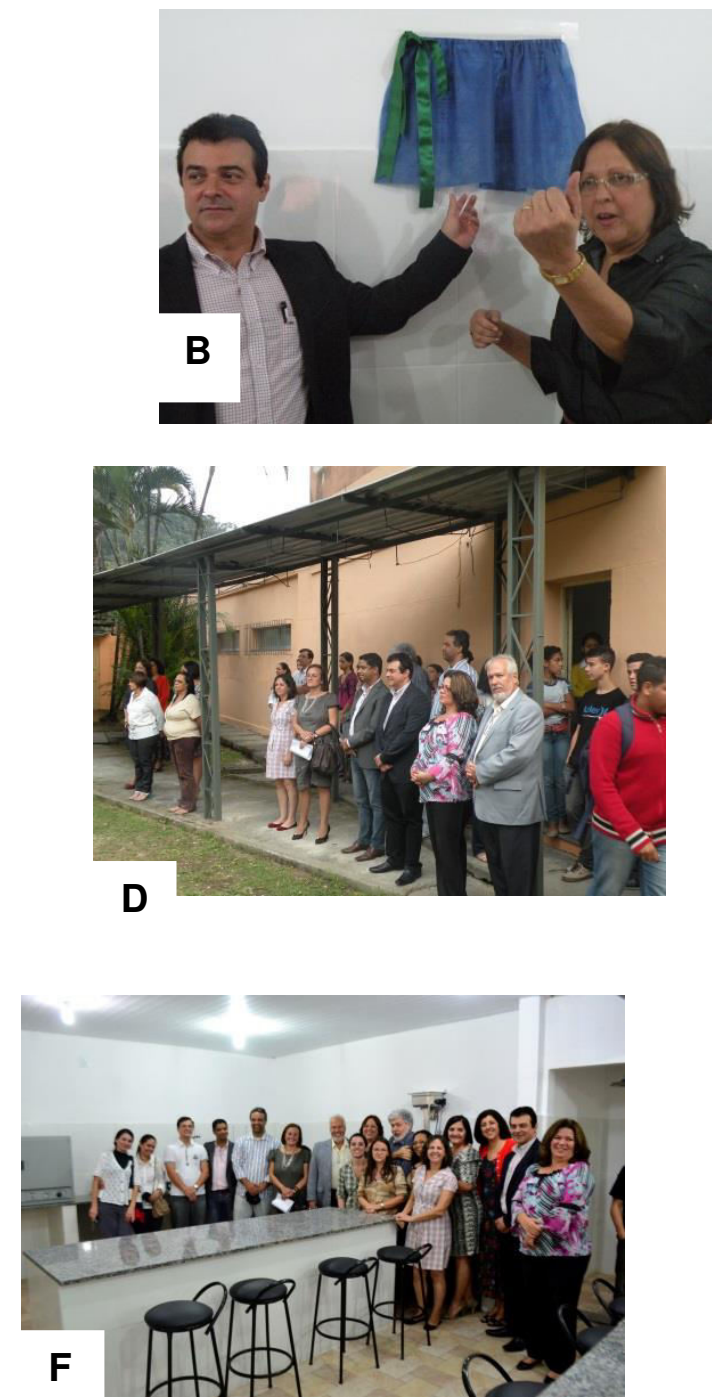

Figura 4. Momentos da cerimônia de inauguração do laboratório químico 


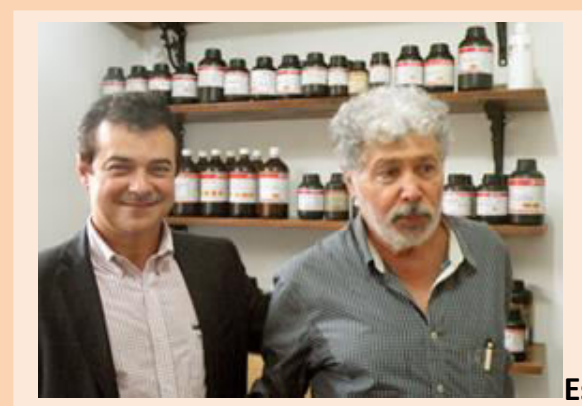

\author{
Divulgação \\ Jerson Lima e o Coordenador do projeto, Angelo \\ C. Pinto, inauguram laboratório em escola em Magé
}

Na última sexta-feira, 6 de setembro, foi inaugurado um laboratório de química na Escola Estadual José Veríssimo, no município de Magé. Depois de haver passado por obras de reforma, ele recebeu novas bancadas, revestimento, equipamentos, reagentes e vidrarias, além de chuveiros de segurança. Em homenagem ao diretor do Instituto de Química da UFRJ recentemente falecido, ele receberá o nome de Joab Trajano Silva. Montado com recursos do edital de Apoio à Melhoria do Ensino, da FAPERJ, o laboratório é parte do projeto "A Química como vocação: Basta melhorá-la no ensino médio", coordenado pelo professor Angelo da Cunha Pinto. Do projeto também faz parte a confecção de kits e cartilhas com experimentos de química, treinamentos de estudantes e a supervisão da disciplina experimental. À inauguração, estiveram presentes o diretor científico da Fundação, Jerson Lima Silva, que ressaltou a forte atuação que a FAPERJ vem tendo nos últimos anos no apoio a ciência, tecnologia e inovação no estado, e o apoio à educação em todos os níveis; Hélder Eterno da Silveira, coordenador geral de Programas de Valorização do Magistério da Educação Básica da Coordenação de Aperfeiçoamento de Pessoal de Nível Superior (Capes); Vitor F. Ferreira, presidente da Sociedade Brasileira de Química; Fernando C. da Silva, secretário da SBQ-Rio; Cassia Tucci, diretora do Instituto de Química da UFRJ; o coordenador do projeto, Angelo da Cunha Pinto; e Bárbara Vasconcelos, subcoordenadora do projeto, além de integrantes da diretoria da escola e membros da Secretaria Estadual de Educação. A certeza de que esse novo laboratório atenderá aos alunos do ensino médio da região com excelente padrão de qualidade foi unanimidade em todos os discursos. As representantes da Secretaria Estadual de Educação e o representante da Capes destacaram que a educação é o ingrediente fundamental para o desenvolvimento do país e que esse desenvolvimento começa pelo município. Também foi enfatizada, pela diretora da escola Maria Angélica, a importância do novo laboratório como forma de despertar vocações, assim como o desejo de que ele possa servir de embrião para um curso técnico em química, além de chamar atenção para a parceria estabelecida com a UFRJ e FAPERJ. ${ }^{6}$

Quadro 2. Nota publicada na FAPERJ sobre a inauguração do laboratório

\subsection{Realização de seminários}

Além da criação do laboratório, a equipe do projeto organizou um ciclo de seminários regulares no Colégio, proferidos por professores e estudantes de Licenciatura em Química da Universidade Federal do Rio de Janeiro. Alguns dos temas abordados até o momento foram:

$>$ Reciclagem de papel e $\mathrm{pH}$, pela estudante do Curso de Licenciatura de Química da Universidade Federal do Rio de Janeiro Aline Camargo Jesus de Souza;

$>$ A Química no nosso cotidiano, pelo professor do Instituto de Química da
Universidade Federal Fluminense Vitor Francisco Ferreira;

$>\mathrm{O}$ abuso das drogas e suas consequências, pela professora do Instituto de Ciências Biomédicas da Universidade Federal do Rio de Janeiro Gisele Zapata-Sudo;

$>\mathrm{O}$ Brasil dos viajantes, pelo professor do Instituto de Química da Universidade Federal do Rio de Janeiro Angelo da Cunha Pinto;

$>$ Cromatografia em papel de corantes presentes em doces: um alerta ao consumo excessivo deste aditivo, pela estudante Curso de Licenciatura de Química da Universidade Federal do Rio de Janeiro Camila Almeida 
Oliveira.

A parceria estabelecida entre o Colégio Estadual José Veríssimo e a Universidade Federal do Rio de Janeiro não foi interrompida com o fim da vigência do projeto aprovado no Edital FAPERJ № $31 / 2012$. A nova fase da parceria consiste no apoio à implantação de um Curso Técnico de Química nos moldes do Programa Dupla Escola no Colégio, o que será de grande importância para Magé e o entorno do Município.

O Curso Técnico de Química será estruturado para atender às exigências do mercado, possibilitando maiores chances dos alunos egressos em conseguirem colocação no mercado de trabalho quando da conclusão do curso.

\section{Conclusão}

A equipe que elaborou a proposta e criou - laboratório Joab Trajano no Colégio José Veríssimo, no Município de Magé, vem sendo desmembrada para atender a outras escolas do estado do Rio de Janeiro. Os recursos obtidos com a aprovação do edital do Programa Apoio à Melhoria do Ensino em Escolas da Rede Pública de 2013, por exemplo, está sendo utilizado para criação de um laboratório de Química no Colégio poeta Mário Quintana, em Nilópolis.

Espera-se que esta iniciativa motive outros pesquisadores da área de Química a contribuírem com seu conhecimento para melhorarem esta disciplina no Ensino Médio e, que em prazo não muito longo, haja outras escolas e colégios nos municípios do Rio de Janeiro com laboratórios de Química. Ensinar Química longe do laboratório é como ensinar a nadar fora da piscina.

É inconcebível que o Brasil com a segunda maior indústria química do continente americano, atrás apenas dos Estados Unidos da América, aceite conviver com o déficit de professores de Química e com escolas e colégios sem laboratórios de Ciências.

A riqueza das nações não está nos seus recursos naturais como muitos afirmam. Não há riqueza maior do que o capital humano. $\mathrm{E}$ pessoas qualificadas e jovens talentos não saem de poços de petróleo ou de minas de diamantes, elas são forjadas nas salas de aulas e nos laboratórios de Ciências.

A aventura apenas começou, e por isso é prematuro alardear o sucesso deste projeto. As próximas avaliações do IDEB do Colégio José Veríssimo e o ingresso de seus alunos nas Instituições Federais de Ensino Superior serão o termômetro para medir o êxito do projeto "A química como vocação: Basta melhorá-la no Ensino Médio".

\section{Referências Bibliográficas}

${ }^{1}$ Galastri, L. A educação no Brasil melhorou. Mas para quem? Revista Galileu, 2013, 08 de agosto. Disponível em: $<$ http://revistagalileu.globo.com/>Acesso em: 30 setembro 2013.

${ }^{2}$ Duarte, A.; Benevides, C. O Globo 2012, 15 de agosto.

${ }^{3}$ Sítio Chancellor Joel Klein's "Children First" New Standard Curriculum for NYC Public Schools.

Disponível em:<http://www.math.nyu.edu/mfdd/braam s/links/cf-blueprint-03.html>. Acesso em: 20 abril 2014

${ }^{4}$ Soares, F. J. Folha de São Paulo, em Tendências e debates 2012, 4 de agosto.

${ }^{5}$ Cruz, P. O Globo 2012, 12 de agosto; Sítio do Instituto Nacional de Estudos e Pesquisas Educacionais. Disponível em:<http://ideb.inep.gov.br>. Acesso em: 15 abril 2014.

${ }^{6}$ Caminhos para a Educação: reflexões e debates do maior Encontro Internacional de Educação, realizado no Brasil em 2011. Organização: Castro, C. M.; Ramos, J. F. Curitiba: Positivo, 2013. 
${ }^{7}$ Pinto, A. C. High school chemistry teaching: How to improve it? Journal of the Brazilian Chemical Society 2012, 23, 985. [CrossRef]

${ }^{8}$ Pinto, A. C. Education: a duty of all. Journal of the Brazilian Chemical Society 2012, 23, 1199. [CrossRef]

${ }^{9}$ Sítio da Coordenação de Pessoal de Nível Superior. Disponível em: <http://www.capes.gov.br/educacaobasica>. Acesso em: 18 abril 2014.

${ }^{10}$ Sítio do Governo do Rio de Janeiro. Disponível em: <http://www.rj.gov.br/web/imprensa/exibec onteudo?article-id=973097>. Acesso em: 18 abril 2014.

${ }^{11}$ Pinto, A. C. Programa de aceleração do crescimento: ensino de ciências. Journal of the Brazilian Chemical Society 2007, 18, editorial. [Link]

${ }^{12}$ Pinto, A. C.; Galembeck, F.; de Andrade, J. B. The Brazilian Chemical Society and the international year of chemistry. Journal of the Brazilian Chemical Society 2012, 23, 373. [CrossRef]

${ }^{13}$ Guarieiro, L. L. N.; Costa, E. A. A.; Victor, M. M.; Riato, V. B.; Lopes, W. A.; Leite, O. D.; Braga, V. S.; Lucena, P. R.; Mangrich, A. S. INCT E\&A conectando educação, ciência e tecnologia. Revista Virtual de Química 2011, 3, 361. [CrossRef]

${ }^{14}$ Pinto, A. C. The Brazilian Chemical Society (SBQ) and the chemistry teaching in high schools. Journal of the Brazilian Chemical Society 2008, 19, editorial. [CrossRef] 